\title{
Performance Analysis of a Stochastic System with Standby Failure and Maintenance
}

\author{
R.K. Bhardwaj \\ Department of Statistics, \\ Punjabi University Patiala \\ Pin-147002, India
}

\author{
Komaldeep Kaur \\ Department of Statistics \\ Punjabi University \\ Patiala \\ Pin-147002, India
}

\author{
S.C. Malik \\ Department of Statistics \\ M. D. University Rohtak \\ Pin-124001, India
}

\begin{abstract}
In industrial systems some components are kept in spare to cope up with the failures of operating components. The failure of these spares too, significantly affects the functioning and outputs of the system. The current paper investigates a semiMarkov model for a redundant system consisting of two identical units and a repair facility. The system starts operating with one unit in operation and remaining in redundancy mode. The failure rate of unit in redundancy is zero, initially. After crossing a pre specified time the redundant unit is expected to fail and thereafter it goes under inspection to check feasibility of maintenance or replacement so that necessary remedial action can be taken. Under this framework the expressions for various measures of system performance are derived exploring the regenerative point technique of renewal theory. A numerical example, for a particular case, illustrates the practical importance of the study graphically.
\end{abstract}

\section{Keywords}

Stochastic system, standby failure, maintenance, regenerative point, performance measures.

\section{AMS Subject Classification MSC2010: 90B25}

\section{INTRODUCTION}

The system engineers and planners, often, use the technique of standby redundancy for enhancing system reliability and availability. As a result, the standby system models have been widely studied in the literature [1-3]. In case of cold standby systems most of the studies, [4- 5], primarily focused only on the readiness of the unit in operation, despite of the fact that in a cold standby system the readiness of standby unit is equally important. If the operative unit fails, immediately it must be replaced by the standby to avoid unnecessary loss. For instance, in an operation theatre the ups must be plunged in to action when there is some interruption in the main power supply, to avoid any eventuality. Thus, the standby unit must be checked to assure its readiness for operation. So far, the cold standby systems with the possibility of standby failure have not been researched adequately. Though, a two unit redundant system with standby failure was discussed by [6]. But they have derived only the mean time and the LaplaceStieltj transforms of the distribution of first time to system down. Though recently [7], have debated on the failure of standby unit with the possibility of renewal. The concepts of maximum operation and repair times have been discussed by some researchers in the literature [8].

As the concept of standby failure is of high practical significance, so needs more consideration. Therefore, keeping this aspect in view, in this paper, we developed a reliability model of a cold-standby system with standby failure, subject to maximum redundancy time. The model consists of two identical units. Initially, one unit is in operation and other in cold-standby mode. After occurrence of failure, the operative unit directly goes under repair. The standby unit goes for inspection to check the feasibility of its maintenance or replacement, after a pre-specified time span. This amount of time is termed as maximum redundancy time. A single repair facility, present in the system, performs the job of repair, inspection, replacement and maintenance. The failure and repair times are assumed to follow exponential distribution whereas repair and maintenance time distributions are taken as arbitrary. The switches, repairs and maintenances are perfect. The random variables associated with failure, repair, replacement and maintenance times are statistically independent. The semi-Markov processes and regenerative point technique are explored to derive the expressions for various measures of system effectiveness such as transition probabilities, mean sojourn times, mean time to system failure, availability, busy period, expected number of visits and profit. For a particular case, graphs are plotted for highlighting the importance of study.

\section{NOTATIONS}

$\begin{array}{lll}\mathrm{N}_{\mathrm{o}} & : & \text { The unit is operative and in normal mode } \\ \mathrm{C}_{\mathrm{s}} & : & \text { The unit is in cold-standby } \\ \mu & : & \text { Failure rate of cold-standby unit } \\ \lambda & : & \text { Failure rate of operative unit } \\ \mathrm{a} / \mathrm{b} & : & \text { Probability that maintenance feasible/ }\end{array}$ replacement feasible
$\mathrm{h}(\mathrm{t}) / \mathrm{H}(\mathrm{t})$
pdf / cdf of inspection time
$\mathrm{g}(\mathrm{t}) / \mathrm{G}(\mathrm{t})$
pdf / cdf of repair time of unit
$\mathrm{m}(\mathrm{t}) / \mathrm{M}(\mathrm{t})$
$\mathrm{pdf} / \mathrm{cdf}$ of maintenance time of unit
$\mathrm{F}_{\mathrm{ui}} / \mathrm{F}_{\mathrm{UI}} \quad:$ Failed unit under inspection /under inspection continuously from previous state

$\mathrm{F}_{\mathrm{wr}} / \mathrm{F}_{\mathrm{WR}}$ : Failed unit waiting for repair / waiting for repair continuously from previous state

$\mathrm{F}_{\mathrm{ur}} / \mathrm{F}_{\mathrm{UR}} \quad: \quad$ Failed unit under repair / under repair continuously from previous state

$\mathrm{F}_{\mathrm{urp}} / \mathrm{F}_{\mathrm{URp}} \quad:$ Failed unit under replacement / under replacement continuously from previous state

$\mathrm{F}_{\mathrm{um}} / \mathrm{F}_{\mathrm{UM}} \quad: \quad$ Failed unit under maintenance / under maintenance continuously from previous state

$\mathrm{F}_{\mathrm{wm}} / \mathrm{F}_{\mathrm{WM}} \quad: \quad$ Failed unit waiting for maintenance/ waiting for maintenance continuously from previous state 
$\mathrm{q}_{\mathrm{ij}}(\mathrm{t}) / \mathrm{Q}_{\mathrm{ij}}(\mathrm{t}) \quad$ : Pdf/cdf of direct transition time from regenerative state $S_{i}$ to regenerative State $S_{j}$ Or failed state $S_{j}$ without visiting any other regenerative state in $(0, \mathrm{t}]$

$\mathrm{q}_{\mathrm{ij} . k r}(\mathrm{t}) / \mathrm{Q}_{\mathrm{ij} . k r}(\mathrm{t}) \quad$ : $\mathrm{pdf} / \mathrm{cdf}$ of first passage time from regenerative state $S_{i}$ to regenerative state $S_{j}$ or failed state $S_{j}$ visiting state $S_{k}, S_{r}$ once in $(0, t]$

$\mu_{\mathrm{i}}(\mathrm{t}) \quad$ : Probability that the system up initially in state $S_{i} \in E$ is up at time $t$ Without visiting to any regenerative state

$\mathrm{W}_{\mathrm{i}}(\mathrm{t}) \quad$ : Probability that server busy in the state $\mathrm{S}_{\mathrm{i}}$ up to time $t$ without making an transition to any other regenerative state or returning to the same state via one or more non-regenerative states

$\mathrm{m}_{\mathrm{ij}} \quad: \quad$ Contribution to mean sojourn time $\left(\mu_{\mathrm{i}}\right)$ in state $S_{i}$ when system transit Directly to state $S_{j}$ so that

$$
\begin{aligned}
& \mu_{\mathrm{i}}=\sum_{\mathrm{j}} m_{\mathrm{ij}} \text { and } \mathrm{m}_{\mathrm{ij}} \\
& =\int \mathrm{td} \mathrm{Q}_{\mathrm{ij}}(\mathrm{t})=-\mathrm{q}_{\mathrm{ij}}^{*^{\prime}}(0)
\end{aligned}
$$

(S) / C : Symbol for Laplace-Stieltjes convolution/Laplace convolution

$\sim / * \quad$ : Symbol for Laplace- stietljes Transform

(LST)/Laplace transform (LT)

'(desh) : Symbol for derivative of the function.

Considering these symbols, the following are possible transition states of the system model

The regenerative states:

$$
\begin{aligned}
& \mathrm{S}_{0}=\left(\mathrm{N}_{\mathrm{o}}, \mathrm{C}_{\mathrm{s}}\right), \quad \mathrm{S}_{1}=\left(\mathrm{F}_{\mathrm{ur}}, \mathrm{N}_{\mathrm{o}}\right), \quad \mathrm{S}_{2}=\left(\mathrm{N}_{\mathrm{o}}, \mathrm{F}_{\mathrm{ui}}\right), \\
& \mathrm{S}_{5}=\left(\mathrm{N}_{\mathrm{o}}, \mathrm{F}_{\mathrm{um}}\right)
\end{aligned}
$$

The non-regenerative states:

$\mathrm{S}_{3}=\left(\mathrm{F}_{\mathrm{UR}}, \mathrm{F}_{\mathrm{wr}}\right), \quad \mathrm{S}_{4}=\left(\mathrm{F}_{\mathrm{wr}}, \mathrm{F}_{\mathrm{UI}}\right), \quad \mathrm{S}_{6}=\left(\mathrm{F}_{\mathrm{WR}}, \mathrm{F}_{\mathrm{um}}\right), \mathrm{S}_{7}=$ $\left(\mathrm{F}_{\mathrm{wr}}, \mathrm{F}_{\mathrm{UM}}\right)$

\section{THE STOCHASTIC MODEL}

\subsection{Transition Probabilities}

Considering the possible states of the system model, the basics of probability theory [9], yields the following expressions for, $P_{\mathrm{ij}} \geq 0$

$$
\begin{aligned}
& P_{\mathrm{ij}}=\mathrm{Q}_{\mathrm{ij}}(\infty)=\int_{0}^{\infty} \mathrm{q}_{\mathrm{ij}}(\mathrm{t}) \mathrm{dt}=\widetilde{\mathrm{Q}}_{\mathrm{ij}}(0) \\
& \mathrm{p}_{01}=\frac{\lambda}{\lambda+\mu^{\prime}} \quad \mathrm{p}_{02}=\frac{\mu}{\lambda+\mu^{\prime}}, \quad \mathrm{p}_{10}=\mathrm{g}^{*}(\lambda), \\
& \mathrm{p}_{13}=1-\mathrm{g}^{*}(\lambda), \quad \mathrm{p}_{20}=\mathrm{bh}^{*}(\lambda), \\
& \mathrm{p}_{24}=1-\mathrm{h}^{*}(\lambda), \quad \mathrm{p}_{25}=\mathrm{ah}^{*}(\lambda), \\
& \mathrm{p}_{31}=\mathrm{g}^{*}(0), \quad \mathrm{p}_{41}=\mathrm{bh}^{*}(0) \\
& \mathrm{p}_{46}=\mathrm{ah}(0), \quad \mathrm{p}_{50}=\mathrm{m}^{*}(\lambda), \\
& \mathrm{m}^{*}(\lambda), \quad \mathrm{p}_{61}=\mathrm{m}^{*}(0) \\
& \mathrm{p}_{71}=\mathrm{m}^{*}(0), \quad \mathrm{p}_{11.3}=1-\mathrm{g}^{*}(\lambda), \\
& \mathrm{p}_{21.4}=\left[1-\mathrm{h}^{*}(\lambda)\right] \mathrm{b}, \quad \mathrm{p}_{21.4,6}=\left[1-\mathrm{h}^{*}(\lambda)\right] \mathrm{a}, \\
& \mathrm{p}_{51.7}=\left[1-\mathrm{m}^{*}(\lambda)\right] \\
& \text { Here it should be noted that }
\end{aligned}
$$

$$
\begin{aligned}
& \mathrm{p}_{01}+\mathrm{p}_{02}=\mathrm{p}_{10}+\mathrm{p}_{13}=\mathrm{p}_{20}+\mathrm{p}_{24}+\mathrm{p}_{25}=\mathrm{p}_{31}=\mathrm{p}_{41}+ \\
& \mathrm{p}_{46}=\mathrm{p}_{50}+\mathrm{p}_{57}=\mathrm{p}_{61}=\mathrm{p}_{71}=\mathrm{p}_{10}+\mathrm{p}_{11.3}=\mathrm{p}_{20}+\mathrm{p}_{25}+ \\
& \mathrm{p}_{21.4}+\mathrm{p}_{21.4,6}=\mathrm{p}_{50}+\mathrm{p}_{51.7}=1
\end{aligned}
$$

\subsection{Mean Sojourn Time}

The unconditional mean time taken by the system to transit to any regenerative state $S_{j}$ when it is counted from epoch of entrance into that state $S_{i}$ is given by;

$$
\mathrm{m}_{\mathrm{ij}}=\int_{0}^{\infty} \operatorname{td}\left\{\mathrm{Q}_{\mathrm{ij}}(\mathrm{t})\right\}=-\mathrm{q}^{*^{\prime}}{ }_{\mathrm{ij}}(0)
$$

Let $\mathrm{T}$ denotes the time to system failure then the mean sojourn time in the state $S_{i}$ is given by;

$$
\mu_{\mathrm{i}}=\mathrm{E}(\mathrm{t})=\int_{0}^{\infty} \mathrm{P}(\mathrm{T}>t) \mathrm{dt}
$$

The following results are obtained

$$
\begin{aligned}
\mu_{0} & =\frac{1}{\lambda+\mu}, \quad \mu_{1}=\frac{\left[1-\mathrm{g}^{*}(\lambda)\right]}{\lambda}, \\
\mu_{2} & =\frac{\left[1-\mathrm{h}^{*}(\lambda)\right]}{\lambda}, \quad \mu_{3}=-\mathrm{g}^{*^{\prime}}(0), \\
\mu_{4} & =-\mathrm{h}^{*^{\prime}}(0), \quad \mu_{5}=\frac{\left[1-\mathrm{m}^{*}(\lambda)\right]}{\lambda}, \\
\mu_{6} & =-\mathrm{m}^{*^{\prime}}(0), \quad \mu_{7}=\mathrm{m}^{*^{\prime}}(0), \\
\mu_{1}^{\prime} & =\left[\frac{1}{\lambda}-\mathrm{g}^{*^{\prime}}(0)\right] \quad\left[1-\mathrm{g}^{*}(\lambda)\right], \\
\mu_{2}^{\prime} & =\left[\frac{1}{\lambda}-\mathrm{h}^{*^{\prime}}(0)-\mathrm{am}^{*^{\prime}}(0)\right]\left[1-\mathrm{h}^{*}(\lambda)\right], \\
\mu_{5}^{\prime} & =\left[\frac{1}{\lambda}-\mathrm{m}^{*^{\prime}}(0)\right]\left[1-\mathrm{m}^{*}(\lambda)\right]
\end{aligned}
$$

Further,

$$
\begin{aligned}
& \mathrm{m}_{01}+\mathrm{m}_{02}=\mu_{0}, \quad \mathrm{~m}_{10}+\mathrm{m}_{13}=\mu_{1}, \\
& \mathrm{~m}_{20}+\mathrm{m}_{24}+\mathrm{m}_{25}=\mu_{2}, \quad \mathrm{~m}_{31}=\mu_{3}, \\
& \mathrm{~m}_{41}+\mathrm{m}_{46}=\mu_{4}, \quad \mathrm{~m}_{50}+\mathrm{m}_{57}=\mu_{5}, \\
& \mathrm{~m}_{61}=\mu_{6}, \quad \mathrm{~m}_{71}=\mu_{7}, \\
& \mathrm{~m}_{10}+\mathrm{m}_{11.3}=\mu_{1}^{\prime}, \\
& \mathrm{m}_{20}+\mathrm{m}_{25}+\mathrm{m}_{21.4}+\mathrm{m}_{21.4,6}=\mu_{2}^{\prime}, \\
& \mathrm{m}_{50}+\mathrm{m}_{51.7}=\mu_{5}^{\prime}
\end{aligned}
$$

\section{SYSTEM PERFORMANCE MEASURES}

\subsection{Mean Time to System Failure}

Let $\phi_{\mathrm{i}}(\mathrm{t})$ be the c.d.f of the first passage time from regenerative state $S_{i}$ to a failed state. Regarding the failed state as absorbing state, we have the following recursive relations for $\phi_{\mathrm{i}}(\mathrm{t})$ :

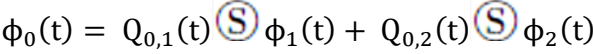

$$
\begin{aligned}
& \phi_{1}(\mathrm{t})=\mathrm{Q}_{1,0}(\mathrm{t}) \text { (S) } \phi_{0}(\mathrm{t})+\mathrm{Q}_{1,3}(\mathrm{t}) \\
& \phi_{2}(\mathrm{t})=\mathrm{Q}_{2,0}(\mathrm{t})(\mathrm{S})_{\phi_{0}}(\mathrm{t})+\mathrm{Q}_{2,4}(\mathrm{t})+ \\
& \mathrm{Q}_{2,5}(\mathrm{t}) \text { (S) } \phi_{5}(\mathrm{t}) \\
& \phi_{5}(\mathrm{t})=\mathrm{Q}_{5,0}(\mathrm{t})(\mathrm{S})_{\phi_{0}}(\mathrm{t})+\mathrm{Q}_{5,7}(\mathrm{t})
\end{aligned}
$$

Taking Laplace- Stieltjes transform of above relation (4.1.1) and solving for $\widetilde{\phi}_{0}(\mathrm{~s})$, then the mean time to system failure is given by

$$
\begin{gathered}
\text { MTSF }=\lim _{s \rightarrow 0} \frac{1-\widetilde{\phi}_{0}(s)}{s}=\frac{\mathrm{N}_{1}}{\mathrm{D}_{1}} \\
\mathrm{~N}_{1}=\mu_{0}+\mathrm{p}_{01} \mu_{1}+\mathrm{p}_{02}\left[\mu_{2}+\mathrm{p}_{25} \mu_{5}\right] \text { And } \\
\mathrm{D}_{1}=1-\mathrm{p}_{01} \mathrm{p}_{10}-\mathrm{p}_{02}\left[\mathrm{p}_{20}+\mathrm{p}_{25} \mathrm{p}_{50}\right]
\end{gathered}
$$




\subsection{Steady State Availability}

Let $\mathrm{M}_{\mathrm{i}}(\mathrm{t})$ is the probability that system is up initially in state is $S_{i} \in E$ is up at time $t$ without visiting any other regenerative state then we have

$$
\begin{aligned}
& M_{0}(t)=e^{-(\lambda+\mu) t}, \quad M_{1}(t)=e^{-\lambda t} \bar{G}(t), \\
& M_{2}(t)=e^{-\lambda t} \bar{H}(t)
\end{aligned}
$$

Let $A_{i}(t)$ be the probability that the system is in up-state at instant ' $\mathrm{t}$ ' given that the system entered regenerative state $\mathrm{S}_{\mathrm{i}}$ at $\mathrm{t}=0$. The recursive relations for $A_{i}(t)$ are as follows

$$
\begin{aligned}
& \mathrm{A}_{0}(\mathrm{t})=\mathrm{M}_{0}(\mathrm{t})+\mathrm{q}_{0,1}(\mathrm{t})\left(C \mathrm{~A}_{1}(\mathrm{t})+\mathrm{q}_{0,2}(\mathrm{t}) \subseteq \mathrm{A}_{2}(\mathrm{t})\right. \\
& \mathrm{A}_{1}(\mathrm{t})=\mathrm{M}_{1}(\mathrm{t})+\mathrm{q}_{1,0}(\mathrm{t}) \subseteq \mathrm{A}_{0}(\mathrm{t})+\mathrm{q}_{1,1.3}(\mathrm{t}) \subseteq \mathrm{A}_{1}(\mathrm{t}) \\
& A_{2}(t)=M_{2}(t)+q_{2,0}(t) \subseteq A_{0}(t)+q_{2,1.4}(t) \subseteq A_{1}(t) \\
& +\mathrm{q}_{2,1.4,6}(\mathrm{t}) \subseteq A_{1}(\mathrm{t})+\mathrm{q}_{2,5}(\mathrm{t}) \subseteq A_{5}(\mathrm{t}) \\
& A_{5}(t)=M_{5}(t)+q_{5,0}(t) \Subset A_{0}(t)+q_{5,1.7}(t) \Subset A_{1}(t)
\end{aligned}
$$

Taking LT of above relation (4.2.1) and solving for $\mathrm{A}_{0}^{*}(\mathrm{~s})$, the steady state availability is given by

$$
\mathrm{A}_{0}(\infty)=\lim _{\mathrm{s} \rightarrow 0} s \mathrm{~A}_{0}^{*}(\mathrm{~s})=\frac{\mathrm{N}_{2}}{\mathrm{D}_{2}}
$$

$\mathrm{N}_{2}=\mathrm{p}_{10} \mu_{0}+\left[1-\mathrm{p}_{02}\left(\mathrm{p}_{20}+\mathrm{p}_{25} \mathrm{p}_{50}\right)\right] \mu_{1}+\mathrm{p}_{02} \mathrm{p}_{10}\left[\mu_{2}+\right.$ p25 25 ,

$\mathrm{D}_{2}=\mathrm{p}_{10} \mu_{0}+\left[1-\mathrm{p}_{02}\left(\mathrm{p}_{20}+\mathrm{p}_{25} \mathrm{p}_{50}\right)\right] \mu_{1}^{\prime}+\mathrm{p}_{02} \mathrm{p}_{10}\left[\mu_{2}^{\prime}+\right.$ $\mathrm{p} 25 \mu 5^{\prime}$

\subsection{Busy Period of Server}

\subsubsection{Due to inspection:}

Let $\mathrm{W}_{\mathrm{i}}^{\mathrm{I}}(\mathrm{t})$ be the probability that the server is busy in state $\mathrm{S}_{\mathrm{i}}$ due to inspection for failure of cold-standby unit upto time $t$ without making any transition to any other regenerative state or returning to the same via one or more non-regenerative states then we have

$$
\mathrm{W}_{2}^{\mathrm{I}}(\mathrm{t})=\mathrm{e}^{-\lambda \mathrm{t}} \overline{\mathrm{H}}(\mathrm{t})+\left(\lambda \mathrm{e}^{-\lambda \mathrm{t}}(\mathrm{C}) \overline{\mathrm{H}}(\mathrm{t})\right.
$$

Again let $\mathrm{B}_{\mathrm{i}}^{\mathrm{I}}(\mathrm{t})$ be the probability that the server is busy in inspection of the unit due to cold-standby failure at an instant ' $t$ ' given that the system entered state $S_{i}$ at time $t=0$. The recursive relations for $\mathrm{B}_{\mathrm{i}}^{\mathrm{I}}(\mathrm{t})$ are as follows

$$
\begin{aligned}
& \mathrm{B}_{0}^{\mathrm{I}}(\mathrm{t})=\mathrm{q}_{0,1}(\mathrm{t})\left(\mathrm{B}_{1}^{\mathrm{I}}(\mathrm{t})+\mathrm{q}_{0,2}(\mathrm{t})\left(\mathrm{B}_{2}^{\mathrm{I}}(\mathrm{t})\right.\right. \\
& \mathrm{B}_{1}^{\mathrm{I}}(\mathrm{t})=\mathrm{q}_{1,0}(\mathrm{t}) \subset \mathrm{B}_{0}^{\mathrm{I}}(\mathrm{t})+\mathrm{q}_{1,1.3}(\mathrm{t}) \subset \mathrm{B}_{1}^{\mathrm{I}}(\mathrm{t})
\end{aligned}
$$

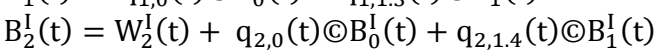

$$
\begin{aligned}
& +\mathrm{q}_{2,1.4,6}(\mathrm{t}) @ \mathrm{~B}_{1}^{\mathrm{I}}(\mathrm{t})+\mathrm{q}_{2,5}(\mathrm{t}) \subseteq \mathrm{B}_{5}^{\mathrm{I}}(\mathrm{t}) \\
& B_{5}^{I}(t)=q_{5,0}(t) \subset B_{0}^{I}(t)+q_{5,1.7}(t) \subset B_{1}^{I}(t)
\end{aligned}
$$

Taking LT of relation (4.3.2), and solving for $\mathrm{B}_{0}^{*^{\mathrm{I}}}(\mathrm{s})$, the time for which server is busy due to inspection is given by

$$
\begin{aligned}
& \mathrm{B}_{0}^{\mathrm{I}}(\infty)=\lim _{\mathrm{s} \rightarrow 0} s B_{0}^{*^{I}}(s)=\frac{N_{3}^{I}}{D_{2}} \\
& \mathrm{~N}_{3}^{\mathrm{I}}=\mathrm{W}_{2}^{*^{\mathrm{I}}}(0)\left\{\mathrm{p}_{02} \mathrm{p}_{10}\right\}
\end{aligned}
$$

\subsubsection{Due to Maintenance}

Let $\mathrm{B}_{\mathrm{i}}^{\mathrm{M}}(\mathrm{t})$ be the probability that the server is busy in maintenance of the unit due to failure at an instant ' $\mathrm{t}$ ' given that the system entered state $\mathrm{S}_{\mathrm{i}}$ at time $\mathrm{t}=0$. The recursive relations for $B_{i}^{M}(t)$ are as follows

$\mathrm{B}_{0}^{\mathrm{M}}(\mathrm{t})=\mathrm{q}_{0,1}(\mathrm{t}) \subseteq \mathrm{B}_{1}^{\mathrm{M}}(\mathrm{t})+\mathrm{q}_{0,2}(\mathrm{t}) \subset \mathrm{B}_{2}^{\mathrm{M}}(\mathrm{t})$
$\mathrm{B}_{1}^{\mathrm{M}}(\mathrm{t})=\mathrm{q}_{1,0}(\mathrm{t}) \subseteq \mathrm{B}_{0}^{\mathrm{M}}(\mathrm{t})+\mathrm{q}_{1,1.3}(\mathrm{t}) \subset \mathrm{B}_{1}^{\mathrm{M}}(\mathrm{t})$

$\mathrm{B}_{2}^{\mathrm{M}}(\mathrm{t})=\mathrm{q}_{2,0}(\mathrm{t}) \subset \mathrm{B}_{0}^{\mathrm{M}}(\mathrm{t})+\mathrm{q}_{2,1.4}(\mathrm{t}) \mathbb{C} \mathrm{B}_{1}^{\mathrm{M}}(\mathrm{t})$

$$
+\mathrm{q}_{2,1.4,6}(\mathrm{t}) \subseteq \mathrm{B}_{1}^{\mathrm{M}}(\mathrm{t})+\mathrm{q}_{2,5}(\mathrm{t}) \subseteq \mathrm{B}_{5}^{\mathrm{M}}(\mathrm{t})
$$

$\mathrm{B}_{5}^{\mathrm{M}}(\mathrm{t})=\mathrm{W}_{5}^{\mathrm{M}}(\mathrm{t})+\mathrm{q}_{5,0}(\mathrm{t}) \subset \mathrm{B}_{0}^{\mathrm{M}}(\mathrm{t})+\mathrm{q}_{5,1.7}(\mathrm{t}) \subset \mathrm{B}_{1}^{\mathrm{M}}(\mathrm{t})$ 4.3.4) Let $\mathrm{W}_{\mathrm{i}}^{\mathrm{M}}(\mathrm{t})$ be the probability that the server is busy in state $\mathrm{S}_{\mathrm{i}}$ due to maintenance of unit upto time $t$ without making any transition to any other regenerative state or returning to the same via one or more non-regenerative states then we get $\mathrm{W}_{5}^{\mathrm{M}}(\mathrm{t})=\mathrm{e}^{-\lambda \mathrm{t}} \overline{\mathrm{M}}(\mathrm{t})+\left(\lambda \mathrm{e}^{-\lambda \mathrm{t}}(\mathrm{C}) \overline{\mathrm{M}}(\mathrm{t})\right.$

Taking LT of relation (4.3.4), and solving for $\mathrm{B}_{0}^{*^{\mathrm{M}}}(\mathrm{s})$, the time for which server is busy due to maintenance is given by

$$
\begin{aligned}
& \mathrm{B}_{0}^{\mathrm{M}}(\infty)=\lim _{\mathrm{s} \rightarrow 0} s B_{0}^{*^{M}}(s)=\frac{N_{3}^{M}}{D_{2}} \\
& \mathrm{~N}_{3}^{\mathrm{M}}=\mathrm{W}_{5}^{* \mathrm{M}}(0)\left\{\mathrm{p}_{25} \mathrm{p}_{02} \mathrm{p}_{10}\right\}
\end{aligned}
$$

\subsubsection{Due to Repair}

Let $\mathrm{W}_{\mathrm{i}}^{\mathrm{R}}(\mathrm{t})$ be the probability that the server is busy in state $\mathrm{S}_{\mathrm{i}}$ due to repairing of unit up to time $t$ without making any transition to any other regenerative state or returning to the same via one or more non-regenerative states and so

$\mathrm{W}_{1}^{\mathrm{R}}(\mathrm{t})=\mathrm{e}^{-\lambda \mathrm{t}} \overline{\mathrm{G}}(\mathrm{t})+\left(\lambda \mathrm{e}^{-\lambda \mathrm{t}}(\mathrm{C}) \mathrm{s}\right) \overline{\mathrm{G}}(\mathrm{t})$

Let $B_{i}^{R}(t)$ be the probability that the server is busy in repairing the unit due to failure at an instant ' $t$ ' given that the system entered regenerative state $S_{i}$ at time $t=0$. The recursive relations for $\mathrm{B}_{\mathrm{i}}^{\mathrm{R}}(\mathrm{t})$ are as follows

$$
\begin{aligned}
& \mathrm{B}_{0}^{\mathrm{R}}(\mathrm{t})=\mathrm{q}_{0,1}(\mathrm{t}) \subseteq \mathrm{B}_{1}^{\mathrm{R}}(\mathrm{t})+\mathrm{q}_{0,2}(\mathrm{t}) \subseteq \mathrm{B}_{2}^{\mathrm{R}}(\mathrm{t}) \\
& \mathrm{B}_{1}^{\mathrm{R}}(\mathrm{t})=\mathrm{W}_{1}^{\mathrm{R}}(\mathrm{t})+\mathrm{q}_{1,0}(\mathrm{t}) \subset \mathrm{B}_{0}^{\mathrm{R}}(\mathrm{t})+\mathrm{q}_{1,1.3}(\mathrm{t}) \subset \mathrm{B}_{1}^{\mathrm{R}}(\mathrm{t}) \\
& \mathrm{B}_{2}^{\mathrm{R}}(\mathrm{t})=\mathrm{q}_{2,0}(\mathrm{t}) \subset \mathrm{B}_{0}^{\mathrm{R}}(\mathrm{t})+\mathrm{q}_{2,1.4}(\mathrm{t}) \subset \mathrm{B}_{1}^{\mathrm{R}}(\mathrm{t}) \\
& +\mathrm{q}_{2,1.4,6}(\mathrm{t}) \subset \mathrm{B}_{1}^{\mathrm{R}}(\mathrm{t})+\mathrm{q}_{2,5}(\mathrm{t}) \subset \mathrm{B}_{5}^{\mathrm{R}}(\mathrm{t}) \\
& \mathrm{B}_{5}^{\mathrm{R}}(\mathrm{t})=\mathrm{q}_{5,0}(\mathrm{t}) \subset \mathrm{B}_{0}^{\mathrm{R}}(\mathrm{t})+\mathrm{q}_{5,1.7}(\mathrm{t}) \subseteq \mathrm{B}_{1}^{\mathrm{R}}(\mathrm{t})
\end{aligned}
$$

Taking LT of relation (4.3.8), and solving for $B_{0}^{*^{R}}(s)$, the time for which server is busy due to repair is given by

$$
\begin{aligned}
& \mathrm{B}_{0}^{\mathrm{R}}(\infty)=\lim _{\mathrm{s} \rightarrow 0} \mathrm{sB}_{0}^{*^{\mathrm{R}}}(\mathrm{s})=\frac{\mathrm{N}_{4}^{\mathrm{R}}}{\mathrm{D}_{2}} \\
& \mathrm{~N}_{4}^{\mathrm{R}}=\mathrm{W}_{1}^{*^{\mathrm{R}}}(0)\left\{1-\mathrm{p}_{02}\left[\mathrm{p}_{20+} \mathrm{p}_{25} \mathrm{p}_{50}\right]\right\} \\
& \text { 4.4 Expected Number of Replacements of } \\
& \text { the Units due to cold-standby failure }
\end{aligned}
$$

\subsection{Expected Number of Replacements of the Units due to cold-standby failure}

Let $\mathrm{R}_{\mathrm{i}}^{\mathrm{C}}(\mathrm{t})$ be the expected number of replacements of the unit failed in cold-standby by the server in $(0, t]$ given that the system entered regenerative state $S_{i}$ at time $t=0$. The recursive relations for $\mathrm{R}_{\mathrm{i}}^{\mathrm{C}}(\mathrm{t})$ are as follows

$$
\begin{aligned}
\mathrm{R}_{0}^{\mathrm{C}}(\mathrm{t})= & \mathrm{Q}_{0,1}(\mathrm{t})\left(\mathrm{S} \mathrm{R}_{1}^{\mathrm{C}}(\mathrm{t})+\mathrm{Q}_{0,2}(\mathrm{t})\left(\mathrm{S} \mathrm{R}_{2}^{\mathrm{C}}(\mathrm{t})\right.\right. \\
\mathrm{R}_{1}^{\mathrm{C}}(\mathrm{t})= & \mathrm{Q}_{1,0}(\mathrm{t})\left(\mathrm{S} \mathrm{R}_{0}^{\mathrm{C}}(\mathrm{t})+\mathrm{Q}_{1,1.3}(\mathrm{t})(\mathrm{S}) \mathrm{R}_{1}^{\mathrm{C}}(\mathrm{t})\right. \\
\mathrm{R}_{2}^{\mathrm{C}}(\mathrm{t})= & \mathrm{Q}_{2,0}(\mathrm{t})(\mathrm{S})\left[1+\mathrm{R}_{0}^{\mathrm{C}}(\mathrm{t})\right]+\mathrm{Q}_{2,1.4}(\mathrm{t})(\mathrm{S})\left[1+\mathrm{R}_{1}^{\mathrm{C}}(\mathrm{t})\right] \\
& +\mathrm{Q}_{2,1.4,6}(\mathrm{t})\left(\mathrm{S} \mathrm{R}_{1}^{\mathrm{C}}(\mathrm{t})+\mathrm{Q}_{2,5}(\mathrm{t})\left(\mathrm{S} \mathrm{R}_{5}^{\mathrm{C}}(\mathrm{t})\right.\right. \\
\mathrm{R}_{5}^{\mathrm{C}}(\mathrm{t})= & \mathrm{Q}_{5,0}(\mathrm{t})\left(\mathrm{S} \mathrm{R}_{0}^{\mathrm{C}}(\mathrm{t})+\mathrm{Q}_{5,1.7}(\mathrm{t})\left(\mathrm{S} \mathrm{R}_{1}^{\mathrm{C}}(\mathrm{t})(4.4 .1)\right.\right.
\end{aligned}
$$

Taking LST of above relation (4.4.1) and solving for $\widetilde{\mathrm{R}}_{0}^{\mathrm{C}}(\mathrm{s})$, the expected number of replacements per unit time to cold-standby failure is given by

$$
\begin{aligned}
& \mathrm{R}_{0}^{\mathrm{C}}(\infty)=\lim _{\mathrm{s} \rightarrow 0} s \tilde{R}_{0}^{C}(s)=\frac{N_{5}^{C}}{D_{2}} \\
& \mathrm{~N}_{5}^{C}=\left[\mathrm{p}_{20}+\mathrm{p}_{21.4}\right] \mathrm{p}_{02} \mathrm{p}_{10}
\end{aligned}
$$

\subsection{Expected Number of Total Visits by the Server}

Let $\mathrm{N}_{\mathrm{i}}(\mathrm{t})$ be the expected number of visits by the server in $(0$, $t]$ given that the system entered the regenerative state $S_{i}$ at $t=0$. The recursive relations for $N_{i}(t)$ are given as 


$$
\begin{aligned}
\mathrm{N}_{0}(\mathrm{t})= & \mathrm{Q}_{0,1}(\mathrm{t})(\mathrm{S})\left[1+\mathrm{N}_{1}(\mathrm{t})\right] \\
& +\mathrm{Q}_{0,2}(\mathrm{t})(\mathrm{S})\left[1+\mathrm{N}_{2}(\mathrm{t})\right] \\
\mathrm{N}_{1}(\mathrm{t})= & \mathrm{Q}_{1,0}(\mathrm{t})(\mathrm{S}) \mathrm{N}_{0}(\mathrm{t})+\mathrm{Q}_{1,1.3}(\mathrm{t})\left(\mathrm{S} \mathrm{N}_{1}(\mathrm{t})\right. \\
\mathrm{N}_{2}(\mathrm{t})= & \mathrm{Q}_{2,0}(\mathrm{t})\left(\mathrm{S} \mathrm{N}_{0}(\mathrm{t})+\mathrm{Q}_{2,1.4}(\mathrm{t})\left(\mathrm{S} \mathrm{N}_{1}(\mathrm{t})\right.\right. \\
& +\mathrm{Q}_{2,1.4,6}(\mathrm{t})(\mathrm{S}) \mathrm{N}_{1}(\mathrm{t})+\mathrm{Q}_{2,5}(\mathrm{t})\left(\mathrm{S} \mathrm{N}_{5}(\mathrm{t})\right. \\
\mathrm{N}_{5}(\mathrm{t})= & \mathrm{Q}_{5,0}(\mathrm{t})\left(\mathrm{S} \mathrm{N}_{0}(\mathrm{t})+\mathrm{Q}_{5,1.7}(\mathrm{t})\left(\mathrm{S} \mathrm{N}_{1}(\mathrm{t})(4.5 .1)\right.\right.
\end{aligned}
$$

Where $S_{j}$ any regenerative state to which the given regenerative state $S_{i}$ transits and $\delta_{j}=1$, if $\mathrm{j}$ is the regenerative state where the server does job afresh otherwise $\delta_{j}=0$. Taking LST of relation (4.5.1) and solving for $\widetilde{\mathrm{N}}_{0}(\mathrm{~s})$. The expected number of total visits per unit time by the server is given by

$$
\mathrm{N}_{0}(\infty)=\operatorname{lims}_{\mathrm{s} \rightarrow 0} \widetilde{\mathrm{N}}_{0}(\mathrm{~s})=\frac{\mathrm{N}_{6}}{\mathrm{D}_{2}}=\frac{\mathrm{p}_{10}}{\mathrm{D}_{2}}
$$

\subsection{Cost Analyses}

The Profit incurred to the system model in $(0, t]$ is given as (Bhardwaj and Singh, 2014)

$P(t)=K_{0} A_{0}(t)-\sum_{i=1}^{5} C_{i} X_{i}(t)$

As $\mathrm{t} \rightarrow \infty$, we obtain the profit attained asymptotically i.e.

$$
\begin{gathered}
P_{0}=\operatorname{Lim}_{t \rightarrow \infty} P(t)=K_{0} A_{0}-\operatorname{Lim}_{t \rightarrow \infty} \sum_{i=1}^{5} C_{i} X_{i}(t) \\
\text { Where } X_{i}(\infty)=\left\{\begin{array}{l}
B_{0}^{I} ; \text { if } i=1 \\
B_{0}^{M} ; \text { if } i=2 \\
B_{0}^{R} ; \text { if } i=3 \\
R_{0}^{C} ; \text { if } i=4 \\
N_{0} ; \text { if } i=5
\end{array}\right.
\end{gathered}
$$

$\mathrm{K}_{0}=$ Revenue per unit up-time of the system

$\mathrm{C}_{1}=$ Cost per unit time for which server is busy in inspection of cold standby unit

$\mathrm{C}_{2}=$ Cost per unit time for which server is busy due to maintenance

$\mathrm{C}_{3}=$ Cost per unit time for which server is busy due to repair $\mathrm{C}_{4}=$ Cost per replacement of the unit

$\mathrm{C}_{5}=$ Cost per unit visit by server

\section{NUMERICAL EXAMPLE}

For illustration, let us assume that all the random variables follow exponential distribution with following probability density functions: $h(t)=\alpha e^{-\alpha t}, g(t)=\beta e^{-\beta t}, m(t)=\theta e^{-\theta t}$. For brevity, let us assume hypothetical values parameters as: $a=0.4, b=0.6, \alpha=0.1, \beta=0.5, \theta=0.3, \mu=0.4$.

Similarly assuming the values for different costs as: $\mathrm{C}_{1}=100$, $\mathrm{C}_{2}=1000, \mathrm{C}_{3}=2000, \mathrm{C}_{4}=6000, \mathrm{C}_{5}=150$. The simulation results are shown in tabular form (tables1, 2, 3) as well as graphs (figure1, 2, 3, 4). Figure-1 displays the behavior of mean time to system failure versus the failure rate $(\lambda)$ of the unit. It shows downward trend with increasing values of both the failure rate $(\lambda)$ as well as the maximum redundancy time $(\mu)$, keeping the values of other parameters as constant. This trend gets inverted with increasing values of repair rate $(\beta)$ and standby maintenance rate $(\theta)$. Figures $2 \& 3$ represent the behaviors of system availability and profit respectively. For different combinations of system parameters both of these systems performance measures exhibit same trend as that of the MTSF. The effect of revenue per unit up time $\left(K_{0}\right)$ on system profit is shown in figure 4. It presents the cut-off points for the system to be profitable. For fixed values of other parameters the system model will be profitable
If $K_{0} \geq 900$ then $\beta=0.8$

If $K_{0} \geq 925$ then $\mu=0.9$

If $K_{0} \geq 945$ then $\theta=0.6$

If $K_{0} \geq 1160$ then $\alpha=0.2$

For $1000 \leq \mathrm{K}_{0} \geq 1050$, the system seems equally profitable for given $\mu$ and $\alpha$ but as $K_{0} \geq 1050$ the system profit due to the effect of $\alpha$ crosses the same due to that of $\mu$.

\section{CONCLUSION AND FUTURE SCOPE}

This paper investigates a probabilistic model of a cold standby system, keeping in view the failure of unit in standby mode subject to maximum time t. The graphical study shows that the failure of standby unit has significant effect on both the reliability as well as profit of the system. The study reveals that the system can be made more reliable and profitable by utilizing the competent service facility of relatively high repair and maintenance rates. The maximum redundancy time should be kept reasonably less so as to check the readiness of standby at an early stage, to reduce system down time. The model developed in this paper, finds its applicability for the reliability professionals working with different kinds of systems such as hydro power plants, remote sensing satellites, ICU's of hospitals etc. In future studies the idea may be explored by incorporating different strategies for inspection, repair and maintenance. The study can be made much more convincing by studying different types of dependencies among the random variables.

\section{ACKNOWLEDGEMENT}

All the authors would like to thank the anonym referees for their valuable suggestions which helped a lot in improving the final draft of the paper. The second author would like to acknowledge the financial help given to her (IF130557) by Govt. of India under INSPIRE Fellowship program of DST

\section{REFERENCES}

[1] Bhardwaj R.K. and Singh, Ravinder, Semi Markov Approach for Asymptotic Performance Analysis of a Standby System with Server Failure, International Journal of Computer Applications 98 (3) (2014), 9-14.

[2] Bhardwaj, R.K., and Singh, Ravinder, Steady state behavior of a cold standby system with server failure and arbitrary repair, replacement \& treatment, International Journal of Applied Engineering Research, Vol. 9(24)(2014), 26563-26578.

[3] Yearout, R.D., Reddy, Prabhakar, and Grosh, Doris Lloyd, Standby redundancy in reliability: a review, IEEE Transactions on Reliability R 35 (3) (1986), 285-292.

[4] Singh, S. K., and Srinivasu, B. Stochastic analysis of a two unit cold standby system with preparation time for repair, Microelectron Reliability 27(1) (1987), 55-60.

[5] Singh, S. K., and Agrafiotis, G. K., Stochastic Analysis of a Two- Unit Cold Standby System Subject to Maximum Operation and Repair Time, Microelectron Reliab 35(12) (1995), 1489-1493.

[6] Osaki, S., Nakagawa, T., On a two-unit standby Redundant system with standby failure, Operations. Research 19 (1971), 510-523.

[7] Bhardwaj R.K., and Kaur, Komaldeep, Reliability and Profit Analysis of a Redundant System with Possible Renewal of Standby Subject to Inspection, International Journal of Statistics and Reliability Engineering 1(1) (2014), 36-46. 
[8] Malik, S. C., Reliability modeling of a computer system with preventive maintenance and priority subject to maximum operation and repair time. Int J Syst Assur Eng Managt. 04 (01) (2013), 94-100.
[9] Feller, W., An introduction to probability theory and its applications, Vol.-I, John Wiley \& Sons Inc., 1968

9. APPENDIX

Table 1: MTSF Trend w.r.t. different parameters

\begin{tabular}{|c|c|c|c|c|c|c|}
\hline $\begin{array}{c}\text { Failure Rate } \\
(\lambda)\end{array}$ & \multicolumn{7}{|c|}{ MTSF } \\
\cline { 2 - 7 } & $\begin{array}{c}\mathrm{a}=0.4, \mathrm{~b}=0.6, \\
\alpha=0.1, \beta=0.5, \\
\theta=0.3, \mu=0.4\end{array}$ & $\mathrm{a}=0.6, \mathrm{~b}=0.4$ & $\alpha=0.2$ & $\beta=0.8$ & $\theta=0.6$ & $\mu=0.9$ \\
\hline 0.1 & 124.2414 & 122.9369 & 141.3921 & 124.2841 & 125.6778 & 110.8025 \\
\hline 0.2 & 63.1980 & 62.5100 & 71.6339 & 63.2472 & 63.9398 & 55.8990 \\
\hline 0.3 & 42.8395 & 42.3595 & 48.3664 & 42.8953 & 43.3467 & 37.5965 \\
\hline 0.4 & 32.6515 & 32.2771 & 36.7211 & 32.7139 & 33.0391 & 28.4440 \\
\hline 0.5 & 26.5310 & 26.2214 & 29.7247 & 26.6001 & 26.8454 & 22.9513 \\
\hline 0.6 & 22.4438 & 22.1785 & 25.0525 & 22.5197 & 22.7083 & 19.2884 \\
\hline 0.7 & 19.5183 & 19.2854 & 21.7084 & 19.6008 & 19.7462 & 16.6709 \\
\hline 0.8 & 17.3187 & 17.1108 & 19.1943 & 17.4076 & 17.5183 & 14.7068 \\
\hline 0.9 & 15.6028 & 15.4149 & 17.2336 & 15.6981 & 15.7799 & 13.1782 \\
\hline
\end{tabular}

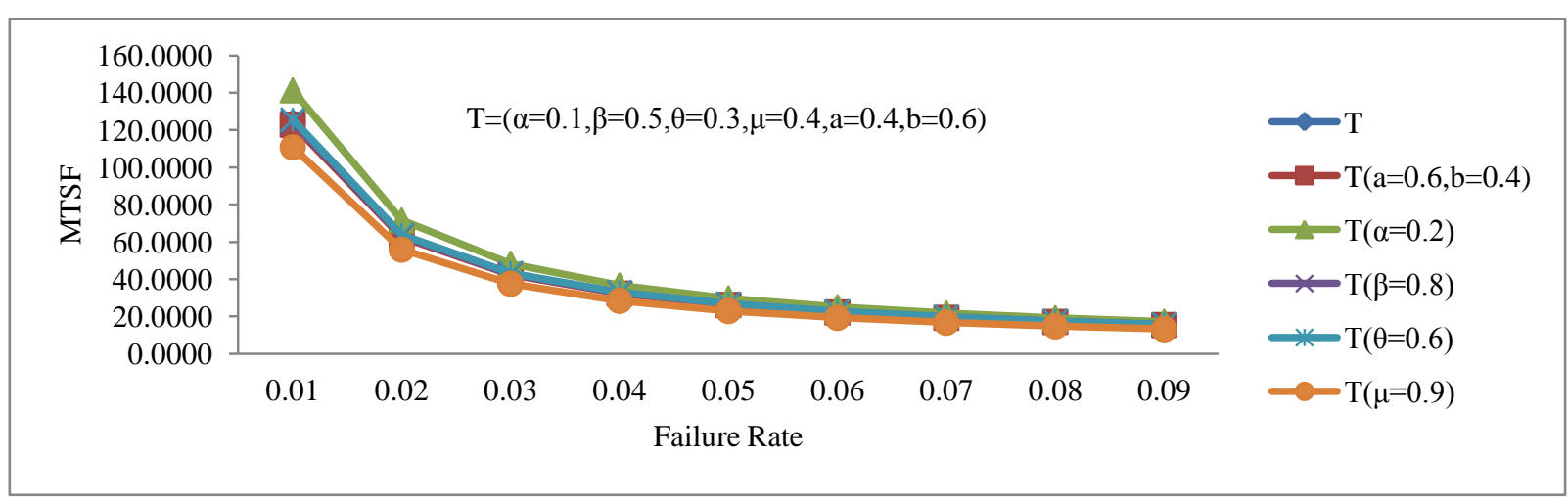

Figure-1: Behavior of MTSF against Failure Rate

Table 2: Availability Trend w.r.t. different parameters

\begin{tabular}{|c|c|c|c|c|c|c|}
\hline $\begin{array}{c}\text { Failure Rate } \\
(\lambda)\end{array}$ & \multicolumn{5}{|c|}{ AVAILABILITY } \\
\cline { 2 - 7 } & $\begin{array}{c}\mathrm{a}=0.4, \mathrm{~b}=0.6, \\
\alpha=0.1, \beta=0.5, \\
\theta=0.3, \mu=0.4\end{array}$ & $\mathrm{a}=0.6, \mathrm{~b}=0.4$ & $\alpha=0.2$ & $\beta=0.8$ & $\theta=0.6$ & $\mu=0.9$ \\
\hline 0.1 & 0.9238 & 0.9218 & 0.9616 & 0.9234 & 0.9266 & 0.9153 \\
\hline 0.2 & 0.8620 & 0.8585 & 0.9276 & 0.8610 & 0.8670 & 0.8467 \\
\hline 0.3 & 0.8110 & 0.8063 & 0.8972 & 0.8090 & 0.8177 & 0.7900 \\
\hline 0.4 & 0.7682 & 0.7626 & 0.8699 & 0.7653 & 0.7762 & 0.7424 \\
\hline 0.5 & 0.7317 & 0.7254 & 0.8452 & 0.7279 & 0.7408 & 0.7019 \\
\hline 0.6 & 0.7004 & 0.6934 & 0.8229 & 0.6956 & 0.7103 & 0.6670 \\
\hline 0.7 & 0.6732 & 0.6656 & 0.8024 & 0.6676 & 0.6838 & 0.6366 \\
\hline 0.8 & 0.6493 & 0.6413 & 0.7837 & 0.6429 & 0.6605 & 0.6100 \\
\hline 0.9 & 0.6282 & 0.6198 & 0.7664 & 0.6211 & 0.6398 & 0.5864 \\
\hline
\end{tabular}




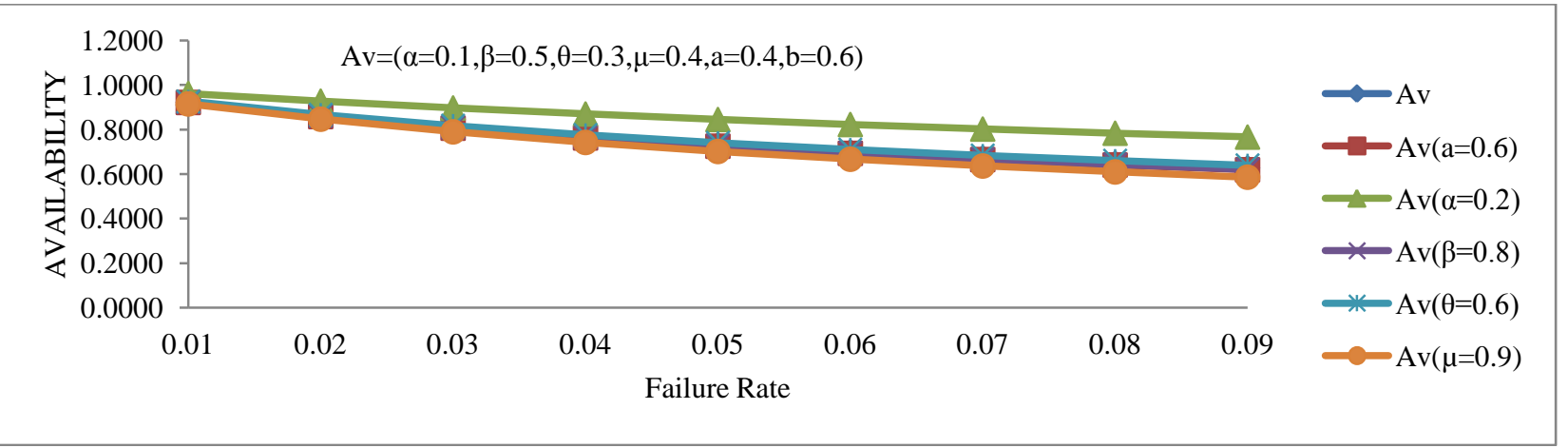

Figure-2: Behavior of Availability against Failure Rate

Table 3: Profit Trend w.r.t. different parameters

\begin{tabular}{|c|c|c|c|c|c|c|}
\hline \multirow[t]{2}{*}{$\begin{array}{l}\text { Failure Rate } \\
\qquad(\lambda)\end{array}$} & \multicolumn{6}{|c|}{$\begin{array}{c}\text { PROFIT } \\
\left(\mathrm{k}_{0}=50000, \mathrm{k}_{1}=100, \mathrm{k}_{2}=1000, \mathrm{k}_{3}=2000, \mathrm{k}_{4}=6000, \mathrm{k}_{5}=150\right)\end{array}$} \\
\hline & $\begin{array}{c}a=0.4, b=0.6, \\
\alpha=0.1, \beta=0.5, \\
\theta=0.3, \mu=0.4\end{array}$ & $\mathrm{a}=0.6, \mathrm{~b}=0.4$ & $\alpha=0.2$ & $\beta=0.8$ & $\theta=0.6$ & $\mu=0.9$ \\
\hline 0.1 & 45727.73 & 45690.49 & 47427.72 & 45722.80 & 45894.06 & 45256.92 \\
\hline 0.2 & 42620.87 & 42510.79 & 45707.22 & 42589.64 & 42891.80 & 41810.02 \\
\hline 0.3 & 40053.16 & 39885.60 & 44170.61 & 39985.67 & 40404.92 & 38961.52 \\
\hline 0.4 & 37896.77 & 37683.07 & 42789.34 & 37789.27 & 38311.88 & 36568.77 \\
\hline 0.5 & 36061.13 & 35809.90 & 41540.38 & 35913.31 & 36526.44 & 34531.02 \\
\hline 0.6 & 34480.29 & 34198.21 & 40404.95 & 34293.75 & 34985.69 & 32775.10 \\
\hline 0.7 & 33105.12 & 32797.45 & 39367.61 & 32882.48 & 33642.68 & 31246.61 \\
\hline 0.8 & 31898.22 & 31569.19 & 38415.51 & 31642.65 & 32461.66 & 29904.24 \\
\hline 0.9 & 30830.68 & 30483.74 & 37537.93 & 30545.55 & 31414.94 & 28716.09 \\
\hline
\end{tabular}

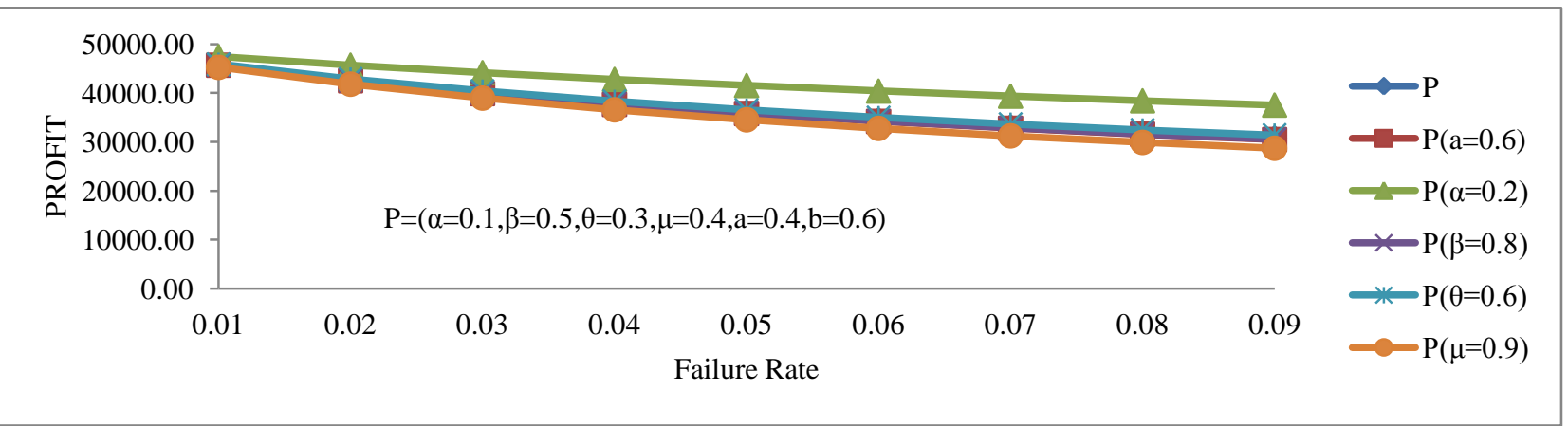

Figure-3: Behavior of Profit against Failure Rate

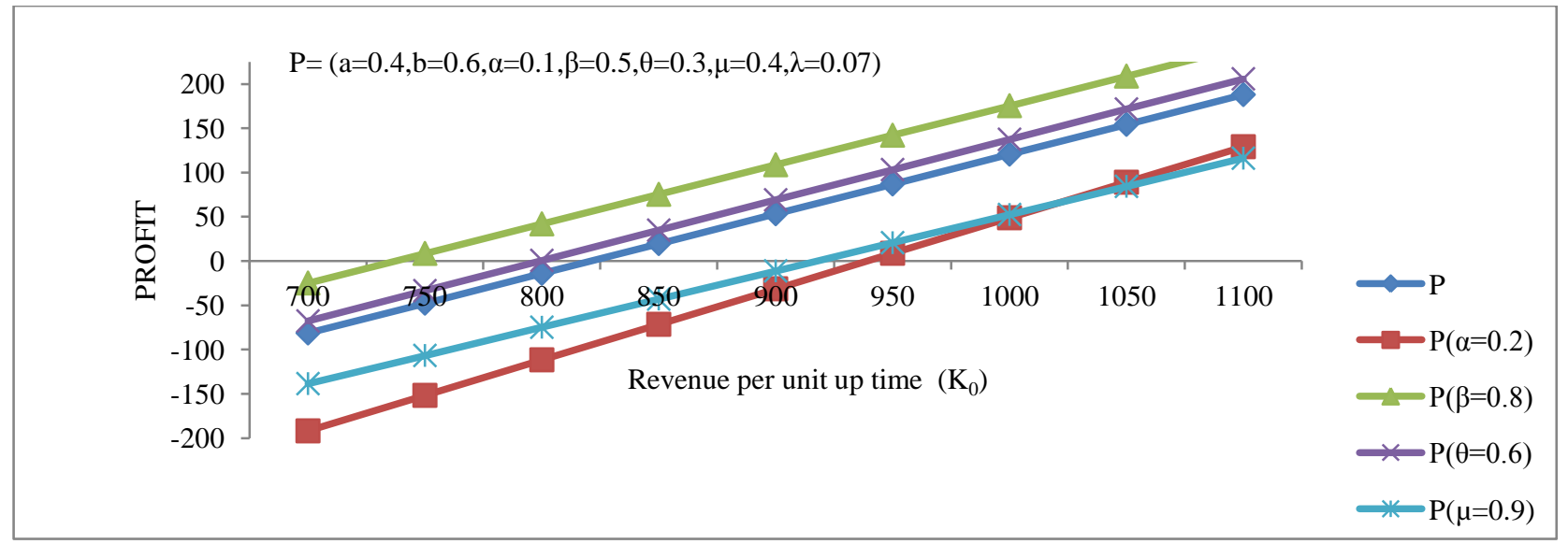

Figure-4: Behavior of Profit against Revenue per unit up time 